Www.jmscr.igmpublication.org

Impact Factor (SJIF): 6.379

Index Copernicus Value: 79.54

ISSN (e)-2347-176x ISSN (p) 2455-0450

crossrefDOI: https://dx.doi.org/10.18535/jmscr/v6i11.73

Journal Of Medical Science And Clinical Research

IGM Publication

An Official Publication of IGM Publication

\title{
Left Ventricular Diastolic Dysfunction in Primary Hypothyroid Patients before and After L-Thyroxine Therapy
}

\author{
Authors \\ Dr PK Agrawal ${ }^{1}$, Dr MP Singh ${ }^{2}$, Dr Faiyaz Alam³ ${ }^{3}$ Dr Usman Rasool ${ }^{4}$, \\ Dr Md. Tabrez Alam ${ }^{4}$, Dr Ahmad Faraz ${ }^{4}$, Dr Raghib Hasan ${ }^{4}$ \\ ${ }^{1}$ Professor and Head, ${ }^{2}$ Professor, ${ }^{3}$ Assiatant Professor, ${ }^{4}$ Post Graduate Trainee \\ Dept. of General Medicine, Katihar Medical College Katihar, Bihar \\ *Corresponding Author \\ Dr Usman Rasool
}

Post Graduate Trainee, Dept. of General Medicine, Katihar Medical College Katihar, Bihar, India

\begin{abstract}
Introduction: Hypothyroidism is the most common form of thyroid disorder throughout the world. It is a clinical state which results from deficient production of thyroid hormonedue to structural and/functional abnormalities. Diastolic dysfunction is defined as left ventricular diastolic dysfunction indicating a functional abnormality of diastolic relaxation, elasticity or distensibility of the left ventricle, regardless of whether the left ventricle ejection fraction is normal or abnormal and whether the patient is symptomatic or not.

Aims and Objectives: The objective of the study will be to examine the effect of thyroid hormone replacement $(L-$ thyroxine) on left ventricular diastolic dysfunction in patients with overt hypothyroidism ${ }^{19}$.

(a) What percentage of hypothyroid patients have left ventricle diastolic dysfunction.

(b) Whether this diastolic dysfunction could be reversed by thyroxine treatment.

(c) To see if any correlation exists between serum TSH and Doppler echocardiography findings regarding diastolic dysfunction of left ventricle.

Materials: Among 120 Hypothyroidism patients 50 patients were found to have Echo-doppler criteria of left ventricular diastolic dysfunction. These 50 patients were finally selected for the study.

Patient with clinical features suggestive of hypothyroidism will be selected from OPD \& IPD of katihar medical college \&hospital. Patient will be assessed clinically \& will be subjected to Thyroid Function Test, Blood Sugar, Lipid Profile, Chest X-Ray, and Echocardiography i.e 2D M Mode and Doppler technique will be used.

50 Patients with raised TSH $(>5 \mathrm{ml} / \mathrm{L} 10)^{64}$ and Echocardiographic finding of left ventricular diastolic dysfunction will be selected for the study.

One hundred and twenty patients were selected from our Medicine and Endocrinology outdoor and indoor medical wards of Katihae Medical College And Hospital. After selection they were evaluated by Doppler echocardiography study. Among 120 patients, 50 patients were found to have Echo-doppler criteria of left ventricular diastolic dysfunction. These 50 patients were finally selected for the study.

Left ventricular diastolic dysfunction was considered when; (Echodoppler criteria)

$E_{\max }$ (early diastolic filling velocity of mitral valve) was decreased compared to $A_{\max }$ (Late diastolic filling velocity of mitral valve) i.e, $E_{\max }<A_{\text {max }}$ and their ratio E/Amax is less ${ }^{63}$ than one $(E / A=1.7+/-0.6$, normal range)

Mitral $E$ wave decleration time (peak of $E$ wave to end of $E$ wave, i.e, DT) and Isovolumic relaxation time(IVRT) with higher than normal values also reflected diastolic dysfunction.(DT=184+/-24msec, IVRT=74+/-26msec,normal range $)^{65}$.

Diastolic Inter Ventricular septal thickness (d-IVST), Diastolic left ventricular posterior wall thickness (d-LVPET),
\end{abstract}


Left ventricular end diastolic diameter (LVEDD) will be evaluated.

50 patient with age sex matched controls will be taken for comparative study to see wheather Left Ventricular Diastolic dysfunction is more common in hypothyroidism.

These 50 patients will be treated with Levothyroxine. After 3 month, Thyroid profile and Echocardiography will be repeated to see if Left ventricular diastolic dysfunction improves with it.

Inclusion Criteria: Aged between 15 to 70 years; With positive clinical history of increased TSH Level.

Exclusion Criteria: valvular abnormalities, Congenital heart disease, Arrhythmias, Hypertrophic cardiomyopathy, Pericardial disease, Ischemic heart disease, LVH, Systemic illness like DM, hypertension.

Duration of study: Dec2016 - May2018.

Results: In this study among 120 hypothyroidism patients 50 patients having diastolic dysfunction. Improvement in the left ventricular diastolic function following L-thyroxine replacement therapy was observed in all the patients during follow-up. After 3 months of treatment along with an increase in $E_{\max }$ (increased from $60.14 \pm 8.12 \mathrm{~cm} / \mathrm{sec}$ to $76.43 \pm 5.26 \mathrm{~cm} / \mathrm{sec}$ ) there was a significant decrease in $A_{\max }$ i.e. late diastolic filling velocity of mitral valve (from $79.40 \pm 11.21 \mathrm{~cm} / \mathrm{sec}$ to $63.76 \pm 10.12 \mathrm{~cm} / \mathrm{sec}$ ), leading to an increase in E/A max ratio from $0.7498 \pm 0.084$ to $1.21 \pm 0.10$. This signified a reversal of the diastolic dysfunction of the left ventricle. There was also a decrease in isovolumic relaxation time from $95.50 \pm 5.92$ to $83.09+6.04 \mathrm{msec}$ (IVRT) and deceleration time of mitral E wave (DT) from $237.26 \pm 14.33 \mathrm{msec}$ to $213.8+10.68 \mathrm{msec}$ - indicating an overall improvement in the diastolic function of the left ventricle. We also found a significant decrease in left ventricular end diastolic diameter (LVEDD), inter ventricular septal thickness (IVST) \& left ventricular .posterior wall thickness (LVPWT) and IVST/LVPWT ratio after 3 months of therapy- suggesting structural changes of left ventricle. But there is slight change in only EF\%. seen.

Conclusion: The subsequent improvement in overall diastolic function of left ventricle in patients with L-Thyroxine therapy was possibily related to continued to biochemical and structural changes in myocardium. However a long term follow up using $2 D$ Echocardiography required.

\section{Introduction}

The Thyroid gland produces two related hormone, thyroxine (T4) and triidiothyronine (T3). Autoimmune disorder of the thyroid gland can stimulate over production of thyroid hormones (thyrotoxicosis) or causes glandular destruction and hormone deficiency (hypothyroidism) ${ }^{1}$ Hypothyroidism is the most common form of thyroid disorder throughout the world. It is a clinical state which results from deficient production of thyroid hormonedue to structural and/functional abnormalities.

Symptoms-weight gain, cold intolerance, fatigue, dry skin, hair loss , menorrhagia, dyspnoea and hoarseness of voice ${ }^{2}$.

Sign- weight gain, puffy face, bradycardia, hypertention, carpel tunnel syndrome, diffuse alopecia.

\section{Doppler Echocardiography \\ Hypothyroidism}

Gupta $\mathrm{A}$ et $\mathrm{al}^{7}$ studied 44 hypothyroid patients and found that inter ventricular septal dimensions were significantly raised $(\mathrm{p}<0.005)$ and mean left ventricular posterior wall thickness was also increased significantly. This showed concentric hypertrophy. Zia Q Farooki et al ${ }^{10}$ studied 11 children with hypothyroidism and found asymmetric septal hypertrophy (ASH), e.g. (Inter ventricular septal thickness: Left ventricular posterior wall diastolic thickness >1.3) present in two children without left ventricular outflow tract obstruction. After thyroxine substitution it reversed to normal.

TK Mishra et al $^{11}$ studied 32 patients and the systolic function of LV was normal in patients with SH. There was significant diastolic dysfunction in the SH patients as compared with controls. There was prolongation of deceleration above time (169+6.1 msec. vs. $148.1+5.4 \mathrm{msec}$ in controls, $\mathrm{p}<0.05)$, isovolumic relaxation time (89.1+7.3 msec vs. 79.4+5.9 msec., $\mathrm{p}<0.05)$, increased A wave $(0.63+0.6 \mathrm{~m} / \mathrm{sec}$. vs. $0.54+0.05$ $\mathrm{m} / \mathrm{sec})$ and reduced E/A ratio $(0.7+0.09$ vs. $1.4+0.3, p<0.05)$. Echocardiography at the end of one year of hormone therapy revealed considerable improvement in diastolic function of the $\mathrm{LV}^{11}$.

\section{Aims and Objectives}

The objective of the study will be to examine the effect of thyroid hormone replacement (L- 
thyroxine) on left ventricular diastolic dysfunction in patients with overt hypothyroidism ${ }^{13}$.

a) What percentage of hypothyroid patients have left ventricle diastolic dysfunction.

b) Whether this diastolic dysfunction could be reversed by thyroxine treatment.

c) To see if any correlation exists between serum TSH and Doppler echocardiography findings regarding diastolic dysfunction of left ventricle.

\section{Material and Methods}

Patient with clinical features suggestive of hypothyroidism will be selected from OPD \& IPD of katihar medical college \& hospital. Patient will be assessed clinically \& will be subjected to Thyroid Function Test, Blood Sugar, Lipid Profile, Chest X-Ray, and Echocardiography i.e 2D M Mode and Doppler technique will be used.

50 Patients with raised TSH $(>5 \mathrm{ml} / \mathrm{L} 10)^{64}$ and Echocardiographic finding of left ventricular diastolic dysfunction will be selected for the study.

One hundred and twenty patients were selected from our Medicine and Endocrinology outdoor and indoor medical wards of Katihar Medical College And Hospital. After selection they were evaluated by Doppler echocardiography study. Among 120 patients, 50 patients were found to have Echo-doppler criteria of left ventricular diastolic dysfunction. These 50 patients were finally selected for the study.

Left ventricular diastolic dysfunction was considered when; (Echodoppler criteria)

$\Rightarrow \quad E_{\max }$ (early diastolic filling velocity of mitral valve) was decreased compared to $A_{\max }$ (Late diastolic filling velocity of mitral valve) i.e, $\mathrm{E}_{\max }<\mathrm{A}_{\max }$ and their ratio $\mathrm{E} / \mathrm{Amax}$ is less $^{63}$ than one $(\mathrm{E} / \mathrm{A}=1.7+/-$ 0.6 , normal range)

$\Rightarrow \quad$ Mitral E wave decleration time (peak of $\mathrm{E}$ wave to end of $\mathrm{E}$ wave, i.e, DT) and Isovolumic relaxation time(IVRT) with higher than normal values also reflected diastolic dysfunction.(DT=184+/-24msec, IVRT $=74+/-26 \mathrm{msec}$, normal range).

$\Rightarrow \quad$ Diastolic Inter Ventricular septal thickness (d-IVST), Diastolic left ventricular posterior wall thickness (d-LVPET), Left ventricular end diastolic diameter (LVEDD) will be evaluated.

50 patients with age sex matched controls will be taken for comparative study to see wheather Left Ventricular Diastolic dysfunction is more common in hypothyroidism.

These 50 patients will be treated with Levothyroxine. After 3 month, Thyroid profile and Echocardiography will be repeated to see if Left ventricular diastolic dysfunction improves with it.

The inclusion criteria were as follows:

$\Rightarrow$ Aged between 15 to 70 years.

$\Rightarrow$ With positive clinical history of increased TSH LEVEL.

The exclusion criteria were as follows :

$\Rightarrow \quad$ Significant valvular abnormalities

$\Rightarrow \quad$ Congenital heart disease

$\Rightarrow \quad$ Arrhythmias eg, chronic atrial fibrillation or flutter

$\Rightarrow \quad$ Hypertrophic cardiomyopathy

$\Rightarrow \quad$ Pericardial disease

$\Rightarrow \quad$ Ischemic heart disease

$\Rightarrow \quad$ Left ventricular hypertrophy

$\Rightarrow \quad$ Systemic illness like diabetes mellitus, hypertension

$\Rightarrow \quad$ Patient not giving consent

Duration of study- Dec2016 - May2018.

Out of 120 hypothyroid patients, 50 patients were found to have Echodoppler evidence of left ventricular diastolic dysfunction. $33 \%$ percentage of hypothyroid patients had echo Doppler evidence of left ventricular diastolic dysfunction as against not a single case of left ventricular diastolic dysfunction in the control group. The age and sex distribution of these 50 hypothyroid patients are shown in Table 1. The age varied from 30 years to 48 years (mean age $38.52+/$ 5.076 years). 


\section{Results}

Out of the 50 hypothyroid patients with left ventricular diastolic dysfunction, we lost follow- up of 8 patients during our study before the first assessment.

Table 1 Change in Serum Thyroid hormone levels before and after treatment of hypothyroid patients with L-thyroxine

\begin{tabular}{|c|c|c|c|}
\hline $\begin{array}{ll}\text { Serum } & \text { Thyroid } \\
\text { Hormone level } & \end{array}$ & $\begin{array}{c}\text { Before treatment } \\
(n=50) \\
(\text { Mean } \pm \text { SD })\end{array}$ & $\begin{array}{c}\text { After } 3 \text { months of } \\
\text { treatment }(n=42) \\
(\text { Mean } \pm \text { SD })\end{array}$ & $P$ value of change \\
\hline $\mathrm{T}_{3}(\mathrm{nmol} / \mathrm{L})$ & $0.85 \pm 0.48$ & $2.14 \pm 0.62$ & $\mathrm{P}<0.01(\mathrm{~S})$ \\
\hline $\mathrm{T}_{4}(\mathrm{nmol} / \mathrm{L})$ & $43.64 \pm 16.37$ & $92.13 \pm 18.35$ & $\mathrm{P}<0.01(\mathrm{~S})$ \\
\hline TSH (miu/L) & $51.33 \pm 30.00$ & $4.41 \pm 1.70$ & $\mathrm{P}<0.01(\mathrm{~S})$ \\
\hline
\end{tabular}

Table 1 compares change in serum thyroid hormone levels in hypothyroid patients before and after treatment. Significant rise was observed in serum T3 level after 3 months of treatment, from $0.85 \pm 0.48$ to $2.14 \pm 0.62$ respectively. Serum T4 level also showed significant rise after 3 months of treatment with L-thyroxine from $43.64 \pm 16.37$ to $92.13 \pm 18.35$ respectively. Serum TSH level show a significant decrease after 3 months of treatment with L-thyroxine from $51.33 \pm 30.00$ to $4.41 \pm 1.70$.

Table 2A Comparison of Echo Doppler findings in hypothyroid patients before and after treatment with Lthyroxine

\begin{tabular}{|c|c|c|c|}
\hline $\begin{array}{lr}\text { Left } & \text { ventricular } \\
\text { diastolic } & \text { function } \\
\text { parameters } & \\
\end{array}$ & $\begin{array}{c}\text { Before treatment } \\
(n=50) \\
(\text { Mean } \pm \text { SD })\end{array}$ & $\begin{array}{c}\text { After } 3 \text { months of } \\
\text { treatment }(n=42) \\
(\text { Mean } \pm \text { SD })\end{array}$ & $\begin{array}{l}P \text { value of } \\
\text { change }\end{array}$ \\
\hline $\mathrm{E}_{\max }(\mathrm{cm} / \mathrm{sec})$ & $60.14 \pm 8.12$ & $76.43 \pm 5.26$ & $\mathrm{P}<0.01(\mathrm{~S})$ \\
\hline $\mathrm{A}_{\max }(\mathrm{cm} / \mathrm{sec})$ & $79.40 \pm 11.21$ & $63.76 \pm 10.12$ & $\mathrm{P}<0.05(\mathrm{~S})$ \\
\hline $\mathrm{E} / \mathrm{A}_{\max }$ ratio & $0.75 \pm 0.08$ & $1.21 \pm 0.10$ & $\mathrm{P}<0.001(\mathrm{~S})$ \\
\hline IVRT (msec) & $95.50 \pm 5.92$ & $83.09 \pm 6.04$ & $\mathrm{P}<0.01(\mathrm{~S})$ \\
\hline $\mathrm{DT}(\mathrm{msec})$ & $237.26 \pm 14.33$ & $213.8 \pm 10.68$ & $\mathrm{P}<0.01(\mathrm{~S})$ \\
\hline
\end{tabular}

Table 2A, compares left ventricular diastolic function parameters in hypothyroid patients before and after treatment with L-thyroxine therapy.

After 3 months of treatment, significant increase was observed in $\mathrm{E}_{\max }$ from $60.14 \pm 8.12$ to $76.43 \pm$ 5.26 , along with a significant decrease in $A_{\max }$ value from $79.40 \pm 11.21$ to $63.76 \pm 10.12$. This led to a significant increase in E/Amax ratio from
$0.75 \pm 0.08$ to $1.21 \pm 0.10$. A significant decrease in IVRT and DT was also observed at the end of 3 months study from $95.50 \pm 5.92$ to $83.09 \pm 6.04$ and $237.26 \pm 14.33$ to $213.8 \pm 10.68$ respectively. So, after 3 months of study there was improvement in all parameters of diastolic function of left ventricle.

Table 2B Comparison of left ventricular dimensions in hypothyroid patients before and after L-thyroxine therapy

\begin{tabular}{|l|c|c|c|}
\hline $\begin{array}{l}\text { Left ventricular } \\
\text { dimensions }\end{array}$ & $\begin{array}{c}\text { Before treatment }(\mathbf{n}=\mathbf{5 0}) \\
(\text { Mean } \mathbf{S D})\end{array}$ & $\begin{array}{c}\text { After 3 months of treatment }(\mathbf{n}=42) \\
(\text { Mean } \pm \text { SD) }\end{array}$ & $\begin{array}{c}\text { P value of } \\
\text { change }\end{array}$ \\
\hline LVEDD $(\mathrm{mm})$ & $44 \pm 4.58$ & $40.36 \pm 4.96$ & $\mathrm{P}<0.01(\mathrm{~S})$ \\
\hline IVST(mm) & $12.38 \pm 3.43$ & $8.62 \pm 1.65$ & $\mathrm{P}<0.01(\mathrm{~S})$ \\
\hline LVPWT $(\mathrm{mm})$ & $10.64 \pm 1.77$ & $9.52 \pm 1.71$ & $\mathrm{P}<0.01(\mathrm{~S})$ \\
\hline IVST/LVPWT ratio & $1.15 \pm 0.16$ & $0.89 \pm 0.052$ & $\mathrm{P}<0.01(\mathrm{~S})$ \\
\hline $\begin{array}{l}\text { Ejection fraction (\%) } \\
(\mathrm{EF})\end{array}$ & $66.90 \pm 4.97$ & $67.98 \pm 4.94$ & $\mathrm{P}>0.05(\mathrm{NS})$ \\
\hline $\mathrm{S}=$ Significant, NS = Not significant & & \\
\hline
\end{tabular}


Table no. 2B reveals that after 3 month of treatment of hypothyroid patients, there was significant decrease in LVEDD, IVST, LVPWT or in IVST/LVPWT ratio. After 3 months of treatment a significant decrease was found in all the aforesaid parameters; LVEDD decreased from $44 \pm 4.58$ to $40.36 \pm 4.96$, IVST decreased from $12.38 \pm 3.43$ to $8.62 \pm 1.65$, simultaneously
LVPWT showed a decrease from $10.64 \pm 1.77$ to $9.52 \pm$ 1.71. A significant decrease was also observed in the IVST/LVPWT ratio from $1.15 \pm$ 0.16 to $0.89 \pm 0.052$. On the other hand, ejection fraction percentage did not show any significant increase after 3 months of treatment that is from $66.90 \pm 4.97$ to $67.99 \pm 4.94$ only.

Table 3A Change in serum triglyceride level in hypothyroid patients (females) before and after treatment with L-thyroxine

\begin{tabular}{|l|c|c|}
\hline $\begin{array}{l}\text { Triglyceride level before } \\
\text { treatment }(\mathbf{n}=\mathbf{3 8}) \\
(\text { Mean } \pm \text { SD) } \mathbf{~ m g / d l}\end{array}$ & $\begin{array}{c}\text { Triglyceride level after 3 } \\
\text { months of treatment }(\mathbf{n}=\mathbf{3 1}) \\
(\text { Mean } \pm \text { SD) } \mathbf{~ m g} / \mathbf{d l}\end{array}$ & P value of change \\
\hline $141.82 \pm 71.68$ & $130.61 \pm 55.65$ & $\mathrm{P}>0.05(\mathrm{NS})$ \\
\hline
\end{tabular}

Table 3B Change in serum triglyceride level in hypothyroid patients (males) before and after treatment with L-thyroxine

\begin{tabular}{|l|c|c|}
\hline $\begin{array}{l}\text { Triglyceride level before } \\
\text { treatment }(\mathbf{n}=\mathbf{1 2}) \\
(\text { Mean } \pm \text { SD) } \mathbf{~ m g} / \mathbf{d l}\end{array}$ & $\begin{array}{c}\text { Triglyceride level after 3 } \\
\text { months of treatment }(\mathbf{n}=\mathbf{1 1}) \\
(\mathbf{M e a n} \pm \mathbf{S D}) \mathbf{~ m g} / \mathbf{d l}\end{array}$ & P value of change \\
\hline $113.92 \pm 37.46$ & $96.82 \pm 19$ & $\mathrm{P}>0.05(\mathrm{NS})$ \\
\hline
\end{tabular}

Table $3 \mathrm{~A}$ and $3 \mathrm{~B}$ depicts the change in serum triglyceride level in male and female hypothyroid patients before and after 3 months of treatment. Mean serum triglyceride level in female patients were higher than normal $(141.82 \pm 71.68)$ before treatment and decreased to $130.61 \pm 55.65 \mathrm{mg} / \mathrm{dl}$ after 3 months of treatment, though the change was statistically not significant, may be a longer follow-up was needed. Similarly, the decrease in mean serum triglyceride in male hypothyroid patients after 3 months of treatment was not significant. However the pretreatment value of mean serum triglyceride in the male patients were within normal limit. A longer follow-up and larger study is needed in this aspect.

Table 3 Change in serum total cholesterol level in hypothyroid patients before and after treatment with Lthyroxine

\begin{tabular}{|l|c|c|}
\hline $\begin{array}{l}\text { Serum total cholesterol level } \\
\text { before treatment }(\mathbf{n = 5 0}) \\
(\text { Mean } \pm \text { SD) } \mathbf{~ m g / d l}\end{array}$ & $\begin{array}{c}\text { Serum total cholesterol level after } \\
\mathbf{3} \text { months of treatment }(\mathbf{n = 4 2}) \\
(\text { Mean } \mathbf{S} \text { SD) } \mathbf{~ m g} / \mathbf{d l}\end{array}$ & P value of change \\
\hline $192.16 \pm 52.43$ & $177.76 \pm 35.76$ & $\mathrm{P}>0.05(\mathrm{NS})$ \\
\hline
\end{tabular}

Table 3 shows the change in serum total cholesterol level in hypothyroid patients before and after 3 months of treatment. Though the pretreatment mean serum total value $(192.16 \pm$ 52.43 ) was within normal limit, $28 \%$ of the hypothyroid patients (Table 12B) showed a serum total cholesterol value above $200 \mathrm{mg} / \mathrm{dl}$. No significant change was observed after 3 months of treatment, may be due to a short follow -up.

Table 4A Percentage of Hypertriglyceridemia in hypothyroid patients before treatment with L-thyroxine Serum Triglyceride Level

$\begin{array}{cc}>160 \mathrm{mg} / \mathrm{dl} & \begin{array}{c}\text { Males } \\ \end{array} \\ & 1 / 12(8.33 \%) \\ & \text { Females } \\ >135 \mathrm{mg} / \mathrm{dl} & 14 / 38(36 \%)\end{array}$


Table 4A, reveals that hypertriglyceridemia was found in $8.33 \%$ of males and $36 \%$ of females before treatment with L-thyroxine.

\section{Discussion}

One hundred and twenty patients with overt hypothyroidism were studied by echo doppler, among which fifty patients with Echo Doppler criteria of left ventricular diastolic dysfunction were finally selected for our study. We lost follow- up of 8 patients during our study before the first assessment. Fifty age \& sex matched normal persons served as a control group.

Change in Serum Thyroid hormone level: Serum TSH level showed a significant decrease in our patients from $51.33+30(\mathrm{~m} \mathrm{Iu} / \mathrm{L})$ to $4.41 \pm 1.7$ (mIu/L) after 3 months of L- thyroxine therapy. Serum $\mathrm{T}_{3} \& \mathrm{~T}_{4}$ showed a significant rise in our patients from $0.85 \pm 0.84(\mathrm{Nmol} / \mathrm{L})$ to $2.14 \pm 0.61$ $(\mathrm{nmol} / \mathrm{L})$ and $43.64 \pm 16.37(\mathrm{Nmol} / \mathrm{L})$ to $92.13 \pm$ $18.35(\mathrm{Nmol} / \mathrm{L})$ respectively after 3 months of treatment.

In our study we found hypertriglyceridemia in $8.33 \%$ of males \& in $36 \%$ of females, hypercholesterolemia was found in $28 \%$ of cases compared to the reports published from Mayo Clinic which found hypertriglyceridemia in $1.5 \%$ and hypercholesterolemia in $56 \%$ of hypothyroid patients. After 3 months of treatment no significant change was observed in mean serum triglyceride or mean serum cholesterol level in our study, although Arem \& Patsch noted a significant change in LDL cholesterol concentration after 4 months of thyroxine therapy in hypothyroid patients. May be a longer follow-up was needed in our patients.

In our study diastolic dysfunction of left ventricle was observed in $38 \%$ of hypothyroid patients. This finding is consistent with that of R. Verma et $\mathrm{al}^{6}$, who found diastolic dysfunction in $27.27 \%$ of overt hypothyroid patients.

Diastolic dysfunction of left ventricle in the pretreatment hypothyroid patients was evident by significantly decreased early diastolic filling velocity of mitral valve $\left(\mathrm{E}_{\max }\right)(60.14 \underline{ \pm} 8.12$ $\mathrm{m} / \mathrm{sec}$ ) compared to significant increase in late diastolic filling velocity of mitral valve- Amax $(79.40 \pm 11.21 \mathrm{~cm} / \mathrm{sec})$ and $\mathrm{E} / \mathrm{A}_{\max }$ ratio of less than one compared to control group. Also isovolumic relaxation time- IVRT $(95.50 \pm 5.92$ $\mathrm{msec}$ ) and mitral E wave deceleration time- DT (237. $26 \pm 14.33)$ were found to be significantly increased in our patients, compared to control group, signifying diastolic dysfunction. Our findings were consistent with that of V. K. Virtamen et $\mathrm{al}^{12}$, who found decreased $\mathrm{E}_{\max }$, increased Amax, E/ $\mathrm{A}_{\max }$ ratio of less than one, increased IVRT and DT in hypothyroid patients before treatment.

Regarding left ventricular dimensions, interventricular septal thickness (IVST), left ventricular posterior wall thickness (LVPWT), IVST /LWPWT ratio \& left ventricular end diastolic diameter (LVEDD) were found increased in the hypothyroid patients before treatment, when compared to control group.

After 3 months of therapy with L-thyroxine, we found a significant increase in $\mathrm{E}_{\max }$ value from $60.14 \pm 8.12 \mathrm{~cm} / \mathrm{sec}$ to $76.43 \pm 5.26 \mathrm{~cm} / \mathrm{sec}$, along with a significant decrease in $\mathrm{A}_{\max }$ value from $79.40 \pm 11.21 \mathrm{~cm} / \mathrm{sec}$ to $63.76 \pm 10.12 \mathrm{~cm} / \mathrm{sec}$. This led to a significant increase in E/A max ratio from $0.7498 \pm 0.084$ to $1.21 \pm 0.10$, signifying that diastolic dysfunction of left ventricle was normalized in the hypothyroid patients after 3 months of L-thyroxine therapy. Simultaneously there was a significant decrease in IVRT and DT after 3 months of therapy from $95.50 \pm 12.02$ $\mathrm{msec}$ to $83.10 \pm 7.49 \mathrm{msec}$ and $237.10 \pm 16.18$ to $213.8 \pm 10.67 \mathrm{msec}$ respectively, implying an overall improvement in left ventricular diastolic function in the study group. Virtanen et $\mathrm{al}^{12}$ found that $E_{\max }$ had a tendency to increase during thyroxine therapy

Regarding left ventricular dimensions a significant decrease was observed in LVEDD, IVST, LVPWT \& IVST/LVPWT ratio from $44+4.58$ $\mathrm{mm}$ to $40.36+4.96 \mathrm{~mm}, 12.38 \pm 3.43 \mathrm{~mm}$ to 8.62 $\pm 1.65 \mathrm{~mm}, 10.64 \pm 1.77 \mathrm{~mm}$ to $9.52 \pm 1.71 \mathrm{~mm}$ and $1.15 \pm 0.16$ to $0.89 \pm 0.052 \mathrm{~mm}$ respectively 
after 3 months of therapy. There was normalizaton of asymmetric septal hypertrophy and concentric hypertrophy as well after 3 months of treatment. These changes in left ventricular dimensions were probably due to structural changes of myocardium, after L-thyroxine substitution therapy.

We found a significant correlation between serum TSH \& IVST/LVPWT ratio and serum TSH \& DT. No significant correlation was observed between serum TSH and $E_{\max }, A_{\max }, E / A_{\max }$ and IVRT. No significant correlation was observed between E/A max ratio and pulse rate neither between $\mathrm{E} / \mathrm{A}_{\max }$ ratio and age. We did not find any significant correlation between the other indices of diastolic dysfunction (i.e., $\mathrm{E}_{\max }, \mathrm{A}_{\max }$, IVRT, and DT) and age or pulse rate.

Preload $\& E_{\max }$ are directly proportional to each other. In our study there was a significant change in left ventricular dimensions (i. e. LVEDD, IVST \& LVPWT) after 3 months of therapy, which led to an improvement in diastolic filling and left ventricular relaxation.

So, in the early stages of thyroxine substitution therapy an increase in the early diastolic filling velocity of mitral valve $\left(E_{\max }\right)$ may be explained by biochemical alterations in the sarcoplasmic reticulum. In the later half of treatment, the overall improvement in the diastolic dysfunction of left ventricle can be contributed both to biochemical $\&$ anatomical changes in the myocardium.

\section{Summary}

Out of one hundred and twenty hypothyroid patients, fifty patients were selected for our study who had echo Doppler evidence of left ventricular diastolic dysfunction. Apart from hypothyroidism there were no other cause to account for their diastolic dysfunction.

Improvement in the left ventricular diastolic function following L-thyroxine replacement therapy was observed in all the patients during follow-up. After 3 months of treatment along with an increase in $\mathrm{E}_{\max }$ ( increased from $60.14+8.12$ $\mathrm{cm} / \mathrm{sec}$ to $76.43 \underline{+5.26} \mathrm{~cm} / \mathrm{sec}$ ) there was a significant decrease in $\mathrm{A}_{\max }$ i.e. late diastolic filling velocity of mitral valve (from 79.40_ $11.21 \mathrm{~cm} / \mathrm{sec}$ to $63.76 \pm 10.12 \mathrm{~cm} / \mathrm{sec}$ ), leading to an increase in $\mathrm{E} / \mathrm{A}$ max ratio from $0.7498 \pm 0.084$ to $1.21 \pm 0.10$. This signified a reversal of the diastolic dysfunction of the left ventricle. There was also a decrease in isovolumic relaxation time from $95.50 \pm 5.92$ to $83.09 \pm 6.04 \mathrm{msec}$ (IVRT) and deceleration time of mitral $\mathrm{E}$ wave (DT) from $237.26+14.33 \mathrm{msec}$ to $213.8+10.68 \mathrm{msec}-$ indicating an overall improvement in the diastolic function of the left ventricle. We also found a significant decrease in left ventricular end diastolic diameter (LVEDD), inter ventricular septal thickness (IVST) \& left ventricular posterior wall thickness (LVPWT) and IVST/LVPWT ratio after 3 months of therapysuggesting structural changes of left ventricle.

The probable mechanism of improvement of left ventricular diastolic dysfunction in the early part of thyroxine replacement therapy was due to biochemical changes i.e. induction of calcium ATPase by L-thyroxine in sarcoplasmic reticulum of myocardial cells. The subsequent improvement in the overall diastolic function of left ventricle was possibly related to continued biochemical \& associated structural changes in the myocardium. So we conclude that diastolic dysfunction of LV is abnormal in patient in hypothyroidism, which can be reversed by L-thyroxine therapy. Doppler echocardiography is reliable, simple and inexpensive method for assessment of diastolic dysfunction. However a long term follow-up is required in this aspect.

\section{Conclusion}

The subsequent improvement in overall diastolic function of left ventricle in patients with LThyroxine therapy was possibily related to continued to biochemical and structural changes in myocardium .However a long term follow up using 2D Echocardiography required. 


\section{Bibliography}

1. J. larry, Susan J Mannden, Anthony P . Weetman. Disorder of the Thyroid Gland .Harrison's Principle Of Internal Medicine; 19edi, Vol2;2283.

2. M N J Strachan ,J.Newell Price; Davidson Principle \& Practice Of Internal Medicine $22^{\text {nd }}$ edi; chp 20, pg 74.

3. E. J. Wayne. Clinical \& metabolic studies in thyroid disease. British Medical Journal; 78 : 78-84, 1960.

4. Jong K Lee, JA Lewis. Myxedema with complete AV block \& Adam Stokes disease abolished with thyroid medication. British Heart Journal; 24 : 253 - 256, 1962.

5. A. Thyroid, 1996 Oct; 6(5) : 397- 402. Cardiac systolic \& diastolic function at rest $\&$ exercise in subclinical hypothyroidismeffect of thyroid hormone therapy. Arem R, Rokey R, Kiefe C, Escalante DA, Rodriguez

6. Varma R, Jain AK et al. Heart in hypothyroidism -An echocardiographic study. J Assoc Physicians India 1996 June, 44(6) : 390-2.

7. Gupta A, Sinha R S et al. Echocardiographic changes \& alterations in lipid profile in cases of sub clinical overt hypothyroidism. J ASSOC Physicians India 1996 Aug, 44(B): 546, 551-3.

8. B.P O' Malley, S. Peterson et al. Reversible abnormalities of myocardial relaxation in hypothyroidism. Journ of Clin Endocrinol Metab. 61 : 269, 1985.

9. T K Mishra, SN Routray, S Das, M Behura- Left ventricular dysfunction in patients with sub clinical hypothyroidism \& its reversibility after hormone therapy- J Assoc Physicians India, 2005 Nov, Vol 53, $943-946$.
10. Zia Q Farooki, William Hoffman et al. Myocardial dysfunction in hypothyroid children. Am. J. Disease. Child, 1983, 137 : 65-68.

11. TK Mishra et el. Left Ventricular dysfunction in patients with subclinical hypothyroidism and its reversibility after hormone therapy. The Journal of the association of physitians of india nov 2005

12. P. Rama Krishnan, Biostatistics, 2001, 148-150, 253-255, Saras Publication, Kanyakumari.

13. Harrison's Principle Of Internal Medicine; 19edi, J. larry, Susan J Mannden , Anthony $\mathrm{P}$. Weetman. Disorder of the Thyroid Gland ; Vol 2 , pg- 2293. 